Marquette University

e-Publications@Marquette

$1-1-2012$

\title{
Who Spends More Online? The Influence of Time, Usage Variety, and Privacy Concern on Online Spending
}

Syed Akhter

Marquette University, syed.akhter@marquette.edu

Accepted version. Journal of Retailing and Consumer Services, Vol. 19, No. 1 (January 2012): 109-115. DOI. (C) 2012 Elsevier B.V. Used with permission. 


\section{Marquette University \\ e-Publications@Marquette}

\section{Marketing Research and Publications/College of Business Administration}

This paper is NOT THE PUBLISHED VERSION; but the author's final, peer-reviewed manuscript. The published version may be accessed by following the link in the citation below.

Journal of Retailing and Consumer Sciences, Vol. 18, No. 1 (2012): 109-115. DOI. This article is (C) Elsevier and permission has been granted for this version to appear in e-Publications@Marquette. Elsevier does not grant permission for this article to be further copied/distributed or hosted elsewhere without the express permission from Elsevier.

\section{Table of Contents}

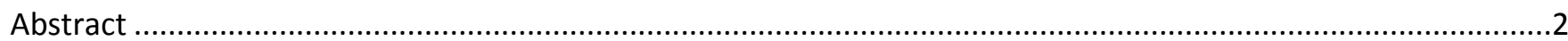

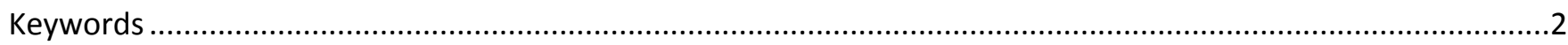

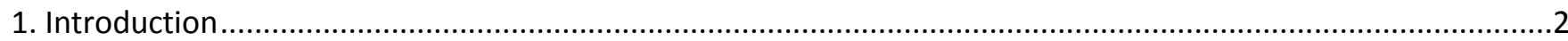

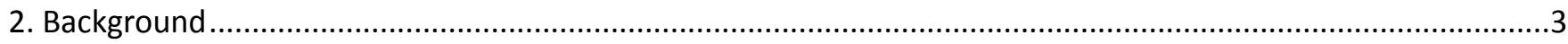

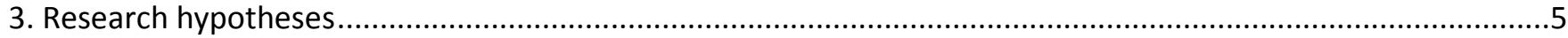

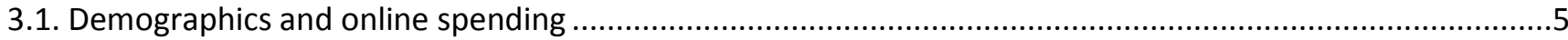

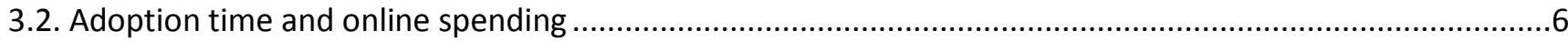

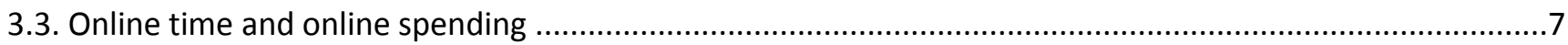

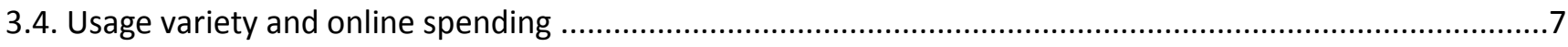

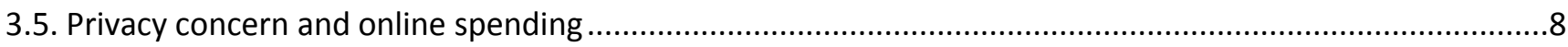

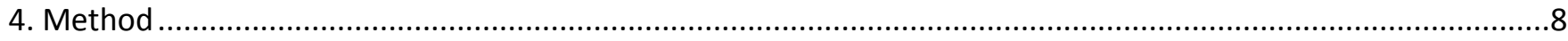

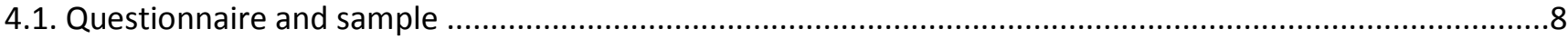

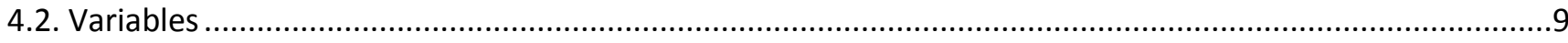

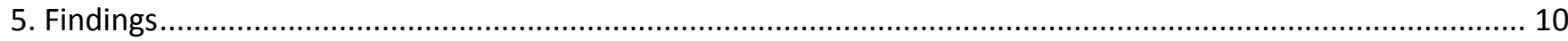

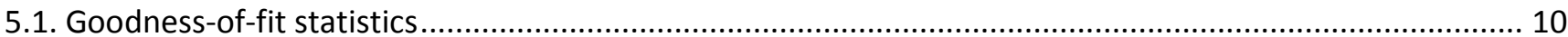

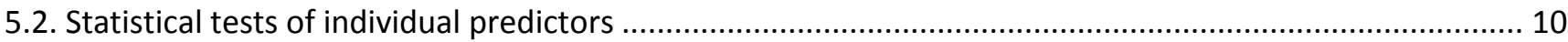




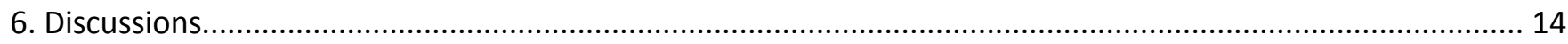

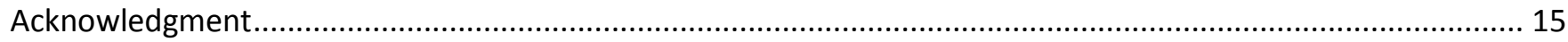

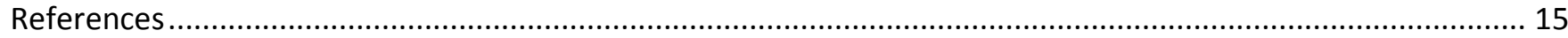

\title{
Who spends more online? The influence of time, usage variety, and privacy concern on online spending
}

\author{
Syed H. Akhter
}

Marketing and International Business, Marquette University, Milwaukee, WI

\section{Abstract}

The paper tests the influence of adoption time, online time, usage variety, and privacy concern on online spending. Findings support the hypothesis that online time, adoption time, and usage variety, the three dimensions of Internet usage experience, have a positive and significant influence on the amount of money consumers spend online, and privacy concern has a negative and significant influence. The control variables included in the model are gender, age, education, and income. Gender, age, and education did not influence online spending. However, income has a significant effect on online spending. Theoretical and strategic implications and recommendations for future research are presented.

Keywords

Online spending, Privacy concern, Internet usage experience

\section{Introduction}

The statistics look impressive for online business. Online sales have grown consistently over the years domestically and globally. In the U.S., the largest online market, total online retail sales reached \$126.7 billion in 2007, increasing from \$4.98 billion in 1998 (U.S. Census Bureau, 2009). Globally, Internet retail sales increased from about \$105 billion in 2004 to approximately \$248 billion in 2009 (Euromonitor, 2010). Some major retailers have also posted impressive growth in online sales. Amazon.com, a full service online retailer, for example, increased sales from \$2.7 billion in 2000 to $\$ 14.8$ billion in 2007, a more than five-fold increase. Others such as Walmart.com and Overstock.com have also increased online sales. The overall growth in online sales reflects the increasing number of 
businesses that now has established an online presence for conducting transactions. Among these are included not only click only companies, but also brick and mortar businesses that have added online platforms to provide multichannel buying options to their customers.

Although the statistics on online sales are encouraging, there remains a major concern among businesses about consumer response to the online channel as online sales have not increased at the predicted rate. The sales performance stands in stark contrast to the predictions that were made soon after the commercialization of the Internet. The expectation was that consumers would flock to online businesses and slowly abandon the traditional retail outlets. Entrepreneurial startups entered the market in large numbers, expecting to tap into the promised potential. Their firms provided huge rebates and discounts but failed to post the expected sales results, not only because of competitive reasons, but also, and more importantly, because of the lack of consumer response. The prediction about consumers showing overwhelming preference for online buying has not materialized yet. Latest data from the U.S. Census Bureau show that online sales accounted for only $3.2 \%$ of overall retail sales in 2007 (U.S. Census Bureau, 2009).

Thus, the major question this paper addresses is what explains online spending. The main thesis of the paper is that adoption time, online time, usage variety, and privacy concern are significant determinants of online spending. While adoption time, online time, and usage variety are hypothesized to affect online spending positively, privacy concern is posited to have a negative effect. By focusing on online spending as the criterion variable, this research contributes to the existing research in three significant ways. First, the paper adds to the extensive literature on product diffusion by focusing on the use of a medium (Internet) after its adoption. Second, in contrast to existing research that has mostly focused on online purchase intentions or attitudes toward online shopping, this paper examines actual online spending. Third, the paper adds to the existing research on online consumer behavior by examining the effects of the three behavioral dimensions of Internet usage experience (adoption time of the Internet, amount of time spent online, and Internet usage variety) on online spending. Furthermore, the inclusion of privacy concern as a determinant of online spending adds a cognitive component to the model. Findings from this study have strategic implications as they will help marketers understand the determinants of online spending, which will help them develop consumer profiles, tailor marketing offerings, and communicate effectively with different segments of Internet users in the market.

To achieve the research goals, this paper is divided into five sections. The first section provides the theoretical background for the selection of the explanatory variables. The second discusses theories and derives the hypotheses. The third covers the method. The fourth presents the findings. The fifth discusses the implications of the findings and identifies substantive issues for future research.

\section{Background}

In the product diffusion model, time plays a key role as the dimension on which different groups of adopters are divided (Rogers, 1995). On the $X$-axis of time, the innovators are the first to adopt a product and the laggards the last. Time is also a crucial variable in the Internet dependency relations model in which consumer-Internet dependency develops over time, which affects the nature and 
extent of online activities (Patwardhan and Yang, 2003). This paper adds to these two streams of research by showing that it is not only product adoption that is influenced by time, but also product usage. As such, the paper covers the second half of the diffusion cycle, that is, how a product is used after it has been adopted. The degree and type of use of a product, the second half of the diffusion cycle, has been identified as a relevant domain of diffusion research, as it also describes the extent of diffusion of an innovation (Robertson and Gatignon, 1986). The paper also adds to the Internet dependency relations model by examining how consumer-Internet interface over time affects the use of a multi-function technological product such as the Internet for a complex activity such as online spending.

The two time-related variables whose effects on online spending are examined in this paper are adoption time and online time. Adoption time is conceptualized as the number of years someone has been using the Internet. It covers the duration of time after a product is adopted. Online time is conceptualized as the consumer-Internet interface and reflects the amount of time people spend using the Internet in a specific time period. It covers the use of the product after it is adopted (Papacharissi and Rubin, 2000). In addition to these two time related variables, this paper also examines the effect of Internet usage. People use the Internet for multiple purposes, such as for communication, education, information acquisition, and entertainment. The variety of activities consumers perform on the Internet can facilitate the transition to online buying and spending. Together, these three independent variables cover the three dimensions of Internet usage experience: duration of use of the Internet, the amount of time spent on the Internet, and the variety of uses of the Internet.

The use of the Internet for making an online purchase requires that consumers provide some personal information to complete the transaction. The information that they provide is stored, analyzed, used, and disseminated by businesses. Consumers are thus concerned not only about how businesses might use the personal data, but also how unauthorized users might access the data base and misuse the data. From the consumer's perspective, privacy concern is embedded in the lack of control over personal information and not knowing how the information they provide will be used. Research shows that privacy concern falls on a continuum with some consumers foregoing online purchases to guard private information while others willingly providing information to get a better deal (Caudill and Murphy, 2000). What is important, however, is that when privacy concern becomes salient, online purchase decision is affected. We, therefore, also examine the effect of privacy concern on online spending.

To determine the effects of the four variables of interest presented above, we control for four demographic variables: gender, age, education, and income. The effects of these four demographic variables have been extensively studied in the literature. However, the findings from this body of research are not unequivocal. Their inclusion in the proposed model further tests their role in affecting online spending. 


\section{Research hypotheses}

\subsection{Demographics and online spending}

Research findings on the effect of gender on online purchasing show mixed results. While some studies show that men are more likely to engage in purchasing online (Teo, 2001; Korgaonkar and Wolin, 1999) and outspend women on the Internet (Lohse et al., 2000), other studies have found that women are more likely to buy on the Internet than men (Goldsmith and Flynn, 2005). Still other studies found that gender was neither a good predictor of online shopping (Patwardhan and Yang, 2003) nor a significant predictor of perceived benefits of computer shopping (Dholakia and Uusitalo, 2002). Attempts to explain gender differences, or the lack thereof, have relied on constructs such as shopping experience, computer anxiety, and attitudes. For example, research shows that women find shopping to be a social and pleasurable activity and are more likely to go shopping with friends or family (Alreck and Settle, 2002). This would suggest that women will be less likely to spend much on online shopping because of its lack of social component. However, recent developments in technology and social networking on the Internet allow shoppers to simulate the social element of buying in an online context and, therefore, can motivate them to buy online. With respect to computer anxiety, some studies find computer anxiety to be high among women (Igbaria and Chakrabarti, 1990), whereas others show no gender differences (Parasuraman and Igbaria, 1990. Given the above considerations, it is hypothesized that gender will have no significant influence on online spending $(\mathrm{H} 1)$.

Age has been considered a factor that influences online consumer behavior, but, like gender, data show lack of uniform relations between age and online buying. Some studies show older consumers to be more likely to buy online and have the highest incidence of online purchasing (Donthu and Garcia, 1999; Korgaonkar and Wolin, 1999), while others find that younger consumers are more likely to shop online (Joines et al., 2003). Still other studies find no correlation between age and Internet buying (Goldsmith and Flynn, 2005; Patwardhan and Yang, 2003).

The underlying rationale for the effect of age on online behavior is traced to both economic situations and attitudinal dispositions. Economic research shows that as people age they have more discretionary income and thus are more likely to spend more on purchases. However, age also affects people's attitudes and behavior (Beatty and Smith, 1987), making them less inclined to adopt new technologies (Gilly and Ziethaml, 1985). This suggests that online buying will not be their preferred mode and that they would continue to be more satisfied with the traditional in-store shopping experiences.

Considering that online buying requires the acquisition of different skill sets, it is hypothesized that age will have a negative influence on online spending $(\mathrm{H} 2)$.

With respect to education, the question is whether education influences online spending. Teo (2001) found no significant relation between education and online purchasing; and Dholakia and Uusitalo (2002) found no significant relation between education and perceived benefits of computer shopping. However, findings from Madden (2003) and Donthu and Garcia (1999) showed a positive influence of education on the likelihood of online buying. Vrechopoulos et al. (2001) also found a positive link between education and Internet shopping. We argue that education will make it easier for people to acquire the skills and knowledge needed to navigate the Internet, and will therefore influence online spending positively. Thus, a positive influence of education on online spending is proposed (H3). 
In understanding relations between income and online spending, two closely connected considerations need to be taken into account, opportunity cost and the convenience of online buying. People with higher income value their time more than people with less income, thus increasing the opportunity cost of time (Goldman and Johansson, 1978). As the opportunity cost of time increases, the goal of saving time in making a purchase becomes an important consideration. This consideration fits well with one of the advantages of online buying. People can sit in the comfort of their home, log on to the Internet, connect with vendors, and shop for products online. This time saving feature of online buying will make online shopping an attractive option for high income people. However, findings on the effects of income on online spending are mixed. Patwardhan and Yang (2003) found income to be not a significant predictor of online shopping. Research also shows that as income increases, the use of the Internet for shopping increases (Donthu and Garcia, 1999). Korgaonkar and Wolin (1999) found a positive correlation between income and online purchases and Lohse et al. (2000) also found that income explained a significant portion of online spending. Considering that higher income people have more discretionary purchasing power and assign higher value to time, a positive influence of income on online spending is proposed $(\mathrm{H} 4)$ :

\section{H1}

Gender has no significant influence on online spending.

\section{$\mathrm{H} 2$}

Age has a negative influence on online spending.

\section{H3}

Education has a positive influence on online spending.

\section{H4}

Income has a positive influence on online spending.

\subsection{Adoption time and online spending}

Papacharissi and Rubin (2000) delineate the three dimensions of Internet usage: the duration of use, amount of use, and type of use of the Internet. These three dimensions reflect Internet usage experience. The duration of use is the adoption time of the Internet and covers the length of time that people have had access to the Internet. The Internet adoption time is linked with the diffusion hypothesis that maps the rate of adoption of a new product with respect to time. When a new product is introduced, very few people (first the innovators and then the early adopters) buy and adopt the product. As time goes by, the adoption rate increases, and the product disseminates into different segments. With respect to the adoption rate, the substantive question is whether the time of adoption of a technological product such as the Internet influences how much people spend buying products online. As the adoption time increases, it is hypothesized that people will tend to explore the different uses of the product, especially of a high technology product such as the Internet. The innovators and 
the early adopters, more open to trying new options and less risk averse, will show higher tendencies to buy products online. Bellman et al. (1999) found the number of months online to be a good predictor of online buying. As the adoption time increases, people will tend to use the Internet for purposes other than emailing or acquiring information. Research has also found that among Internet users, the technology innovators are more favorably disposed to buying online (Long et al., 2003). Time is, therefore, not only a good predictor of product adoption rate but also of product usage. That is, with the passage of time, people will use a high technology product such as the Internet for more complex activities such as buying online. Thus, the following is proposed:

\section{H5}

Adoption time has a positive influence on online spending.

\subsection{Online time and online spending}

Making an online purchase is different from an offline purchase as it requires different kinds of knowledge and skills that consumers acquire over time with an increase in usage intensity. The amount of time people spend using the Internet within a specific time period such as a week is referred to as online time. Research shows that as online time increases, people gain knowledge and feel comfortable in using the Internet for different purposes. The experience gained in using the Internet enhances perceived self-efficacy, which plays a determining role in influencing behavior such as online shopping and spending (Li and Chuan, 2010). Citrin et al. (2000) found that higher levels of Internet usage positively influenced online shopping. Lohse et al. (2000) found that as online time increased, the probability of making an online purchase also increased. Thus, the following is proposed:

\section{H6}

Online time has a positive influence on online spending.

\subsection{Usage variety and online spending}

Internet usage differences are regularly reported in surveys conducted by private and public organizations. The Pew Internet \& American Life Project report shows the variety of use of the Internet with significant usage variations among different groups (Pew Internet, 2010). Usage variety is one of the three dimensions of Internet usage experience and the tasks performed can range from simple to complex tasks and from single use to multiple uses (Dutton et al., 1985). Consumer research shows a positive relation between innovative and varied use of the Internet and online buying (Citrin et al., 1999). Hannah and Lybecker (2010) also found that the varied use of the Internet is a strong determinant of online purchasing. As online buying is a more complex type of activity than emailing or chatting, the use of the Internet for a variety of tasks gives consumers the confidence to buy and spend online. Citrin et al. (2000) tested the variety of use hypothesis and found that consumers who used the Internet for communication, education, and/or entertainment purposes more frequently were also more likely to engage in electronic commerce. The finding also generalized to a different context. Hui and Wan (2004), for example, found that Singaporeans who used the Internet for purposes other than 
shopping were also more likely to use the Internet for shopping. Therefore, we propose that the variety of use of the Internet will affect online spending positively:

\section{H7}

Usage variety has a positive influence on online spending.

\subsection{Privacy concern and online spending}

The online retail environment is different from the brick and mortar retail store in some significant ways. In a traditional retail setting, consumers interact face-to-face with salespeople and pay cash, if they so choose, for the merchandise they buy. However, this is not possible when they buy online. A requirement of making an online transaction is that consumers must provide some private information before they can buy anything. Therefore, from consumers' perspective, losing control over the personal information they provide and not knowing how it will be used become a major concern. Yankelovich Partners found that $79 \%$ of the respondents leave the websites when asked to provide private information, and $90 \%$ reported that privacy was the most pressing concern (Phelps et al., 2001). Consumers also fear that companies will misuse personal information (Caudill and Murphy, 2000), which further inhibits online purchases. Privacy concern has also been found to reduce the use of direct marketing (Milne and Boza 1999) and the intensity of catalog purchase behavior (Phelps et al., 2001). In survey after survey, consumers mention privacy concern as a major factor that negatively affects their online buying decision. Thus, the following is proposed:

\section{H8}

Privacy concern has a negative influence on online spending.

\section{Method}

The hypothesized relations between independent and dependent variables were tested in the ordinal regression model, using the PASW Statistics 18 statistical package. The statistical procedure tested whether the three dimensions of Internet usage experience (Internet adoption time, online time, usage variety) and privacy concern significantly affect the amount of money spent online, after controlling for four demographic variables such as gender, age, education, and income.

\subsection{Questionnaire and sample}

A list of randomly generated 5000 Internet subscribers in three Midwest states in the United States was obtained from an Internet mailing list providers. The list provider maintains an updated list of Internet subscribers to sell to clients such as businesses and academic institutions. A survey questionnaire was mailed to these 5000 subscribers. Following the initial mailing of the questionnaire, a postcard was mailed reminding people to respond to the questionnaire. The total number of responses received was 1,190. A listwise deletion procedure was used to generate the data set for the statistical analysis. The listwise deletion procedure is recommended because the analysis is conducted with the same number of cases (Kline, 2005). The usable sample size after listwise deletion was 1,097, which represented a response rate of $22 \%$. 


\subsection{Variables}

Eight independent variables were included in the proposed model. Among these eight were four control variables (gender, age, education, and income). Gender was coded as (0) male and (1) female. Age was divided into six groups, under 19, between 20 and 34, between 35 and 54, between 55 and 64 , between 65 and 84, and over 84 years, and correspondingly coded as 1 to 6 . Education was divided into seven groups, less than $9^{\text {th }}$ grade, $9^{\text {th }}$ to $12^{\text {th }}$ grade, high school graduate, some college but no degree, associate degree, bachelor's degree, and graduate or professional degree, and correspondingly coded as 1 to 7 . Income was divided into nine groups, under $\$ 14,999$, between 15,000 and $\$ 24,999$, between 25,000 and $\$ 34,999$, between $\$ 35,000$ and $\$ 49,999$, between $\$ 50,000$ and $\$ 74,999$, between $\$ 75,000$ and $\$ 99,999$, between $\$ 100,000$ and $\$ 149,999$, between $\$ 150,000$ and $\$ 199,999$, and over $\$ 200,000$, and correspondingly coded as 1 to 9 . These four control variables were treated as factors.

The variables of interest were Internet adoption time, Internet online time, Internet usage variety, and privacy concern. New product adoption has been defined as the degree to which a consumer adopts a new product relatively earlier than others (Rogers and Shoemaker, 1971). The construct has generally been operationalized in three different ways: new product ownership in a given category, purchase intention, and the relative time of adoption (Foxall, 1988; Wang et al., 2008; Midgley and Dowling, 1993). Following Midgley and Dowling (1993) and Park and Jun (2003), we take the behavioral approach and operationalize adoption time as the relative time of adoption and thus measure it as the number of years respondents had been using the Internet. Respondents were given six options to select from: less than 1 year, 1-2 years, 2-4 years, 4-6 years, 6-8 years, and over 8 years. Online time, one of the three dimensions of Internet usage experience, is operationalized as the amount of time people spend using the Internet. Following Park and Jun (2003), the construct was measured as the average number of hours spent online per week. Respondents were given the following options: under

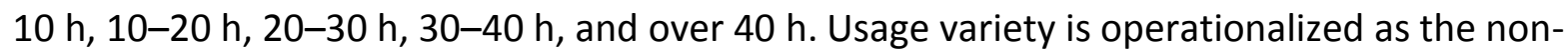
transactional use of the Internet. Citrin et al. (2000) and Hui and Wan (2004) operationalized the construct by averaging responses on the use of the Internet for sending emails for communication and using the Internet for education or for entertainment. We extend their measure by adding information acquisition to communication, entertainment, and education. We also include two indicators for each category, except for education, which is measured by one indicator. On a scale of 0-7, with 0 indicating not at all and 7 indicating very frequently, respondents were asked to indicate how frequently they used the Internet for the following purposes: emailing and chatting (communication), acquiring general and product related information (information acquisition), playing games and downloading music (entertainment), and researching for educational resource (education). The responses to these seven items were averaged to form a single variable. Privacy concern arises because of the perceived loss of control over personal data and the potential for its misuse. Thus, issues such as protection and security of data on the Internet become salient. Phelps et al. (2001) measured privacy concern by asking respondents how concerned they were about the ways companies use personal information. The respondents could choose one of the four options: not very concerned, somewhat concerned, very concerned, or neither concerned nor unconcerned. We use a multiple indicators approach and measure privacy concern by aggregating responses to the following three items on a 7-point Likert scale, anchored by strongly disagree and strongly agree: I am concerned about my privacy on the Internet, privacy is protected on the Internet (reverse coded), Internet is secure for confidential information (reverse coded). These four variables of interest were treated as covariates. The 
dependent variable was the amount of money spent online. Respondents were given six choices: none, under $\$ 25$, between $\$ 25$ and $\$ 50$, between $\$ 50$ and $\$ 75$, between $\$ 75$ and $\$ 100$, and over $\$ 100$. As the respondents were not asked to specify the actual amount of money they spent online but to select one of the six categories, the dependent variable was treated as an ordinal variable with higher categories indicating increasing online expenditures.

\section{Findings}

\subsection{Goodness-of-fit statistics}

Table 1 provides the model-fitting information that shows a highly significant reduction in the chisquare statistics $(p<.005)$, indicating that the proposed model is a significant improvement over the baseline or intercept model. This indicates that we can reject the null hypothesis that the model without the predictors is as good as the model with the proposed predictors. Table 2 shows the goodness-of-fit statistics, which test whether the observed data are consistent with the proposed model. The large $p$-values show that the fit hypothesis cannot be rejected.

Table 1. Model fitting information.

$\begin{array}{lllll}\text { Model } & \begin{array}{l}\mathbf{- 2} \log \\ \text { likelihood }\end{array} & \text { Chi-square } & \text { df } & \text { Sig. } \\ \text { Intercept only } & 3429.627 & & & \\ \text { Final } & 3201.428 & 228.200 & 23.000\end{array}$

Table 2. Goodness-of-fit.

$\begin{array}{llll} & \text { Chi-square } & \text { df } & \text { Sig. } \\ \text { Pearson } & 5553.771 & 5432 & .122 \\ \text { Deviance } & 3198.655 & 5432 & 1.000\end{array}$

\subsection{Statistical tests of individual predictors}

In ordinal regression, the assumption that the regression coefficients are the same for all categories of the dependent variable needs to be tested. The assumption is evaluated through the test of parallel lines, which compares the ordinal model with one set of coefficients for all thresholds (null hypothesis) to a model with a separate set of coefficients for each threshold (general). If the general model gives a significantly better result than the proportional odds model, the assumption of proportional odds is rejected. Since the observed significance level is large ( $p>.05)$, the assumption of parallelism cannot be rejected (see Table 3 ). We next discuss the parameter estimates. 
Table 3. Test of parallel lines.

Model $\quad-2$ log likelihood Chi-square df Sig.

Null hypothesis $\quad 3201.428$

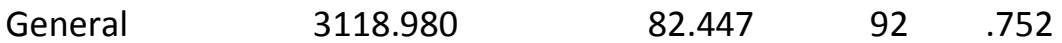

The first hypothesis that gender will have no significant impact on online spending was supported. When it comes to spending money on online shopping, gender does not affect online spending. The finding is in line with those of Patwardhan and Yang (2003) and Dholakia and Uusitalo (2002) who found no significant gender difference. The second hypothesis that age will have a negative impact on online spending was not supported. The parameters were not significant. Goldsmith and Flynn (2005) and Patwardhan and Yang (2003) also found no correlation between age and Internet buying. The third hypothesis that education will have a positive impact on online spending was not supported. The parameters were not significant. The argument that education makes it easier for people to navigate the Internet and leads to greater spending was not supported. Teo (2001) and Dholakia and Uusitalo (2002) also found no significant relation between education and online purchasing and perceived benefits of online purchasing. The fourth hypothesis that income will have a significant influence on online spending was supported. The finding that income has a significant influence on online spending is similar to what Donthu and Garcia (1999), Korgaonkar and Wolin (1999), and Lohse et al. (2000) also found. The parameters show that people with less income are more likely to be in lower online spending categories. In other words, as income increases online spending also increases.

After controlling for the four demographic variables (gender, age, education, and income), the variables of interest are significantly related to online spending. These findings support the four main hypotheses proposed in the study. Internet adoption time, online time, and usage variety have a positive and significant influence on online spending, and privacy concern has a negative and significant influence on online spending (see Table 4). We discuss the findings and the implications in the discussions section below.

Table 4. Parameter estimates.

Estimate Std. error Wald df Sig.

Threshold

$\begin{array}{llllll}\text { Online spend=1.00 } & -1.068 & .399 & 7.164 & 1 & .007 \\ \text { Online spend=2.00 } & .227 & .399 & .324 & 1 & .569 \\ \text { Online spend=3.00 } & .953 & .400 & 5.686 & 1 & .017\end{array}$




\begin{tabular}{|c|c|c|c|c|c|}
\hline Online spend $=4.00$ & 1.331 & .400 & 11.063 & 1 & .001 \\
\hline Online spend $=5.00$ & 1.760 & .401 & 19.222 & 1 & .000 \\
\hline \multicolumn{6}{|l|}{ Location } \\
\hline Adoption time & .096 & .027 & 12.920 & 1 & .000 \\
\hline Online time & .214 & .036 & 35.256 & 1 & .000 \\
\hline Net usage variety & .162 & .034 & 22.811 & 1 & .000 \\
\hline Privacy concern & -.039 & .009 & 18.342 & 1 & .000 \\
\hline Gender $=.00$ & .082 & .069 & 1.399 & 1 & .237 \\
\hline Gender $=1.00$ & $0^{\mathrm{a}}$ & & & 0 & \\
\hline Age $=1.00$ & .197 & .240 & .674 & 1 & .412 \\
\hline Age $=2.00$ & .211 & .226 & .868 & 1 & .352 \\
\hline Age $=3.00$ & .269 & .213 & 1.595 & 1 & .207 \\
\hline Age $=4.00$ & .191 & .218 & .772 & 1 & .380 \\
\hline Age $=5.00$ & $0^{\mathrm{a}}$ & & & 0 & \\
\hline Education $=1.00$ & .213 & .370 & .333 & 1 & .564 \\
\hline Education $=2.00$ & -.268 & .274 & .950 & 1 & .330 \\
\hline Education $=3.00$ & -.006 & .119 & .002 & 1 & .962 \\
\hline Education $=4.00$ & .178 & .102 & 3.072 & 1 & .080 \\
\hline Education $=5.00$ & .044 & .127 & .120 & 1 & .729 \\
\hline Education $=6.00$ & .133 & .103 & 1.649 & 1 & .199 \\
\hline Education $=7.00$ & $0^{\underline{a}}$ & & & 0 & \\
\hline Income $=1.00$ & -1.619 & .305 & 28.224 & 1 & .000 \\
\hline Income=2.00 & -1.508 & .286 & 27.909 & 1 & .000 \\
\hline
\end{tabular}




$\begin{array}{cccccr}\text { Income }=3.00 & -1.643 & .284 & 33.346 & 1 & .000 \\ \text { Income }=4.00 & -1.186 & .268 & 19.554 & 1 & .000 \\ \text { Income }=5.00 & -1.166 & .265 & 19.418 & 1 & .000 \\ \text { Income }=6.00 & -1.142 & .271 & 17.742 & 1 & .000 \\ \text { Income }=7.00 & -.749 & .271 & 7.634 & 1 & .006 \\ \text { Income }=8.00 & -.516 & .306 & 2.839 & 1 & .092 \\ \text { Income }=9.00 & 0 . & & & 0 & \end{array}$

Variables:

Online spend: Amount of money spent online.

Adoption time: Relative time of the adoption of the Internet.

Online time: Number of hours spent using the Internet per week.

Net usage variety: Using the Internet for information acquisition, communication, entertainment, and education.

Privacy concern: Concern about privacy, protection of privacy, and security of the Internet for confidential information.

Gender: Male or female.

Age: Divided into six groups.

Education: Divided into seven groups.

Income: Divided into nine groups.

a

The parameter is set to zero because it is redundant.

Although the findings presented above suggest that the three dimensions of Internet usage experience (adoption time, online time, and usage variety) and privacy concern are both significant and in the hypothesized direction, the limitations of the study need to be noted. First, the study examined the 
amount of spending per month as the dependent variable, which did not cover the number or types of purchases made. Therefore, it could be argued that although variables such as gender, age, and education did not affect online spending, they could influence the types of purchases made or the frequency of purchases. Second, the study examined reported measures of behaviors associated with Internet usage experience. Thus, while we understand the linkages between the three dimensions of Internet usage experience and online spending, we need cognitive data to interpret relations at a deeper level.

\section{Discussions}

Findings from this study show that with respect to online spending, men and women, young and old, and the less and more educated individuals are not significantly different from each other. These three demographic characteristics are found to be not good predictors of online spending. Income, however, has a significant effect on online spending. Given that people with more income will generally spend more money on purchases than people with less income, this finding is not surprising. We can expect the income effect to persist as people with more money will either buy more frequently or purchase more expensive items, thus increasing the amount of money they spend online. This outcome is in line with the findings in behavioral economics and consumer behavior that show a close and positive association between income and expenditures.

After controlling for the demographic variables, the research goal was to examine the influence of the three dimensions (adoption time, online time, and usage variety) of Internet usage experience on online spending. Both adoption time and online time significantly influenced online spending, as hypothesized. People who have had access to the Internet longer than others are more likely to spend more on online purchases. Furthermore, people who spend more time online are also more likely to spend more money on online purchases. Findings from this study suggest that these two time-related variables are good predictors of online spending. The significance of these two variables also suggests that over time online purchases will continue to increase. Usage variety is also positive and significant and thus a good predictor of online spending. People who use the Internet for communication, entertainment, information acquisition, and education more than others are also more likely to spend more than others on online purchases. The findings are significant for firms that are investing in Internet infrastructure development, hoping to capitalize on the expected change in the buying behavior of consumers, especially with respect to developing a preference for making purchases online. However, there is a cautionary note in the findings. Firms will have to address the issue of privacy related to online purchases. One of the significant findings of this study is that privacy concern has a negative influence on online spending. The concern seems justified. News about people losing personal information to hackers is quite common. The huge amount of data that businesses collect on their customers is viewed as being vulnerable to unauthorized access due to human errors or lack of effective security measures at the firm to protect such data. The loss of private information often result in unauthorized purchases or other misuses, causing unwarranted consternation and problems to people whose data were compromised. Findings from this study show that people who are concerned about privacy spend less on online purchases. 
The profile that emerges from this study is that people who spend more money on online purchases have had access to the Internet for a long time, spend more time online, use the Internet for a variety of purposes, and are less concerned about privacy. For businesses, there are several strategic implications of this profile. As access to the Internet increases, they will see a favorable shift among consumers to online stores for making purchases. This will result in a greater percentage of expenditures being allocated to online purchases. The convenience of shopping online, coupled with the economy of the purchase, will bring more consumers to online vendors. However, this conclusion comes with a caveat. Businesses will need to adopt more effective measures to safeguard the data they collect and, more importantly, to assure customers that the data they provide are secure and protected.

Future research can extend the literature by examining four different aspects of online buying. First, we did not explore the psychological factors underlying online time and usage variety. While research on product adoption provides meaningful insights into the characteristics of the different groups of Internet adopters, the psychological factors underlying online time and usage variety have not been adequately examined. Specifically, what consumer characteristics explain variations in the time spent online and usage variety? This interface is a rich area for research. Second, research can focus on how household composition and time commitment to work, education, and other activities affect online spending. Third, existing research shows that self-efficacy influences the use of the Internet for different purposes. However, the relation between self-efficacy and online purchases has not been explored adequately in existing research and could be explored further. A fourth promising area involves the question of how consumer and product characteristics interact to influence online purchases. This study focused on understanding variations in online spending, not what consumers buy online and why. The questions of what consumers buy online and why they buy them are interesting questions, both theoretically and strategically.

\section{Acknowledgment}

I thank the anonymous reviewers for their comments and suggestions.

\section{References}

Alreck and Settle, 2002 P. Alreck, R.B. Settle

\section{Gender effects on internet, catalogue and store shopping}

Journal of Database Marketing, 9 (2) (2002), pp. 150-162

Beatty and Smith, 1987 S. Beatty, S. Smith

External search effort: an investigation across several product categories

Journal of Consumer Research, 14 (1) (1987), pp. 83-95

Bellman et al., 1999 S. Bellman, G.L. Lohse, E.J. Johnson

Predictions of online buying behavior 
Communications of the ACM, 42 (12) (1999), pp. 32-38

Caudill and Murphy, 2000 E.M. Caudill, P.E. Murphy

Consumer online privacy: legal and ethical issues

Journal of Public Policy \& Marketing, 19 (1) (2000), pp. 7-19

Citrin et al., 1999

Citrin, A.V., Sprott, D.E., Silverman, S.N., Stem Jr., D.E., 1999. From Internet use to Internet adoption: is general innovativeness enough? In: Anil Menon, Arun Sharma (Eds.), 1999 AMA Educators' Conference Proceedings. American, Marketing Association, Chicago, pp. 232-233.

Citrin et al., 2000 A.V. Citrin, D.E. Sprott, S.N. Silverman, D.E. Stem Jr.

Adoption of internet shopping: the role of consumer innovativeness

Industrial Management+Data Systems, 100 (7) (2000), p. 294

Dholakia and Uusitalo, 2002 R.R. Dholakia, O. Uusitalo

Switching to electronic stores: consumer characteristics and the perception of shopping benefits

International Journal of Retail and Distribution Management, 30 (10) (2002), pp. 459-469

Donthu and Garcia, 1999 N. Donthu, A. Garcia

The internet shopper

Journal of Advertising Research, 39 (2) (1999), pp. 52-58

Dutton et al., 1985 W. Dutton, P. Kovaric, C. Steinfield

Computing in the home: a research paradigm

Computers and the Social Sciences, 1 (1985), pp. 5-18

Euromonitor, 2010

Euromonitor, 2010. Euromonitor International From Trade Sources/National Statistics.

Foxall, 1988 G.R. Foxall

Consumer innovativeness: novelty seeking, creativity, and cognitive style

E.C. Hirschman, J.N. Sheth (Eds.), Research in Consumer Behavior, 3, JAI Press, Greenwich, CT (1988), pp. 79-113

Gilly and Ziethaml, 1985 M.C. Gilly, V.A. Ziethaml 
The elderly consumer and adoption of technologies

Journal of Consumer Research, 12 (4) (1985), pp. 353-357

Goldman and Johansson, 1978 Goldman, J.K. Johansson

Determinants of search for lower prices: an empirical assessment of the economics of information theory

Journal of Consumer Research, 5 (3) (1978), pp. 176-186

Goldsmith and Flynn, 2005 R.E. Goldsmith, L.R. Flynn

Bricks, clicks, and pix: apparel buyers' use of stores, internet, and catalogs compared

International Journal of Retail and Distribution Management, 33 (4) (2005), pp. 271-283

Hannah and Lybecker, 2010 B. Hannah, K.M. Lybecker

Determinants of recent online purchasing and the percentage of income spent online

International Business Research, 3 (4) (2010), pp. 60-71

Hui and Wan, 2004 T.K. Hui, D. Wan

The role of consumer innovativeness in the adoption of Internet shopping in Singapore

The Internet Business Review, 1 (2004), pp. 2-18

Igbaria and Chakrabarti, 1990 M. Igbaria, A. Chakrabarti

Computer anxiety and attitudes towards microcomputer use

Behavior and Information Technology, 9 (3) (1990), pp. 229-241

Joines et al., 2003 J.L. Joines, C.W. Scherer, D.A. Scheufele

Exploring motivations for consumer web use and their implications for e-commerce

Journal of Consumer Marketing, 20 (2) (2003), pp. 90-108

Kline, 2005 R.B. Kline

Principles and Practice of Structural Equation Modeling

The Guilford Press, New York, NY (2005)

Korgaonkar and Wolin, 1999 P.K. Korgaonkar, L.D. Wolin

A multivariate analysis of web usage

Journal of Advertising Research, 39 (2) (1999), pp. 53-68 
Li and Chuan, 2010 Pei-Fen. Li, M. Chuan

Effects of individual differences on choice strategy in goal-directed online shopping

The Journal of Academy of Business, 15 (2) (2010), pp. 186-192

$\underline{\text { Long et al., } 2003}$

Long, M., Schiffman, L., Sherman, E., 2003. Exploring the dynamics of online retail-related activities. In retailing 2003: strategic planning in uncertain times. In: Proceedings of the Seventh Triennial Retailing Conference. Academy of Marketing Sciences, Columbus, Ohio, November, 2003.

Lohse et al., 2000 G.L. Lohse, S. Bellman, E.J. Johnson

Consumer buying behavior on the internet: findings from panel data

Journal of Interactive Marketing, 14 (1) (2000), pp. 15-29

Madden, 2003 M. Madden

America's On-Line Pursuits: The Changing Picture of Who's On-Line and What they Do

Pew Internet and American Life Project (2003) (p. 54)

Midgley and Dowling, 1993 D.F. Midgley, G.R. Dowling

A longitudinal study of product form innovativeness: the interaction between predisposition and social measures

Journal of Consumer Research, 19 (1993), pp. 611-625

Milne and Boza, 1999 G.R. Milne, M.E. Boza

Trust and concern in consumers' perceptions of marketing information management practices

Journal of Interactive Marketing, 13 (1) (1999), pp. 5-24

Patwardhan and Yang, 2003 P. Patwardhan, J. Yang

Internet dependency relations and online consumer behavior: a media system dependency theory perspective on why people shop, chat, and read news online

Journal of Interactive Advertising, 3 (2) (2003), pp. 57-69

Papacharissi and Rubin, 2000 Z. Papacharissi, A.M. Rubin

Predictors of Internet use

Journal of Broadcasting \& Electronic Media, 44 (2) (2000), pp. 175-196 
Parasuraman and Igbaria, 1990 S. Parasuraman, M. Igbaria

An examination of gender differences in the determinants of computer anxiety and attitudes towards microcomputers among managers

International Journal of Man-Machine Studies, 32 (1990), pp. 327-340

Park and Jun, 2003 C. Park, J.-K. Jun

A cross-cultural comparison of Internet buying behavior: effects of Internet usage, perceived risks, and innovativeness

International Marketing Review, 20 (5) (2003), pp. 534-553

Pew Internet, 2010

Pew Internet, 2010. Pew Internet \& American Life Project, $\_$ www.pewinternet.org/Reports/2010/Generations-2010/Overview.aspx $\rangle$.

Phelps et al., 2001 J.E. Phelps, G. D'Souza, G.J. Nowak

Antecedents and consequences of consumer privacy concerns: an empirical investigation Journal of Interactive Marketing, 14 (4) (2001), pp. 2-17

Robertson and Gatignon, 1986 T.S. Robertson, H. Gatignon

Competitive effects of technology diffusion

Journal of Marketing, 50 (3) (1986), pp. 1-12

Rogers, 1995 E.M. Rogers

Diffusion of Innovations (4th ed.), The Free Press, New York, NY (1995)

Rogers and Shoemaker, 1971 E.M. Rogers, F.F. Shoemaker

Communication of Innovations

The Free Press, New York, NY (1971)

Teo, 2001 T.S.H. Teo

Demographic and motivation variables associated with internet usage activities

Internet Research, 11 (2) (2001), p. 125

$\underline{\text { U.S. Census Bureau, } 2009}$

U.S. Census Bureau, 2009. Stats, 2007 E-Commerce Multi Sector Report, May 28. 
Vrechopoulos et al., 2001 A.P. Vrechopoulos, G.F. Siomkos, G.I. Doukidis

Internet shopping adoption by Greek consumers

European Journal of Innovation Management, 4 (3) (2001), pp. 142-152

Wang et al., 2008 G. Wang, W. Dou, N. Zhou

Consumption attitudes and adoption of new consumer products: a contingency approach European Journal of Marketing, 42 (1-2) (2008), pp. 238-254 